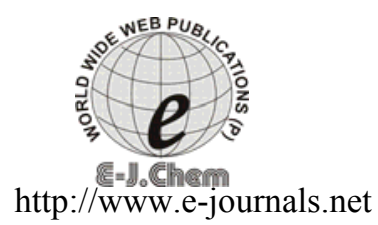

ISSN: 0973-4945; CODEN ECJHAO

E-Journal of Chemistry

http://www.e-journals.net

2011, 8(S1), S363-S371

\title{
Removal of Malachite Green from Aqueous Solution by Activated Carbon Developed from Cocoa (Theobroma Cacao) Shell - A Kinetic and Equilibrium Studies
}

\author{
C. THEIVARASU* and S.MYLSAMY \\ Department of Chemistry, PSG College of Technology \\ Coimbatore - 641 004, India \\ theivarasu@yahoo.co.in
}

Received 12 May 2011; Accepted 15 July 2011

\begin{abstract}
The removal of malachite green (MG) by cocoa (Theobroma cacao) shell activated carbon (CSAC) was investigated in present study. Adsorption studies were performed by batch experiments as a function of process parameters such as initial $\mathrm{pH}$, contact time, initial concentration and adsorbent dose. A comparison of kinetic models applied to the adsorption of MG on CSAC was evaluated for the pseudo-first order and pseudo-second order kinetic models. Results showed that the pseudo-second order kinetic model was found to correlate the experimental data well. The experimental equilibrium adsorption data was represented with Langmuir, Freundlich, Tempkin, DubininRadushkevich and Flory-Huggins isotherms. The experimental data obtained in the present study indicated that activated carbon developed from cocoa shell can be attractive options for dye removal from waste water.
\end{abstract}

Keywords: Adsorption, Malachite Green, Cocoa shell, Kinetics, Isotherm

\section{Introduction}

Dyeing industries are the largest sector of chemical industries in India. Over $7 \times 10^{5}$ tons and approximately 10000 different types of dyes and pigments are produced worldwide annually ${ }^{1}$. Dyes used as colouring materials are toxic to aquatic organisms when unspent substances are discharged into the environment. It is estimated that $10 \%$ of the dye is lost in the effluent during the dyeing process ${ }^{2}$. The treatment process for removing dyes from waste water comprises ozonation ${ }^{3}$, coagulation ${ }^{4}$, ultrafiltration ${ }^{5}$, oxidation ${ }^{6}$, photocatalytic degradation $^{7}$ and adsorption ${ }^{8}$. Adsorption has been found highly efficient for removal of color from wastewater in terms of initial cost, ease of operation and simplicity of design? Adsorption using activated carbon is the most widely used technique because of excellent 
adsorption efficiency for organic compounds ${ }^{10}$. Activated carbon is a highly porous material; therefore it has an extremely high surface area for contaminant adsorption. The equivalent surface area of 1 pound of activated carbon ranges from 60 to $150 \mathrm{acres}^{11}$. In recent years due to high cost of activated carbon, attention has prompted interest in the production of carbon based adsorbents from agricultural waste products ${ }^{12}$. The production of activated carbon from wastes saves the non renewable natural resources and producing a valuable product with potential applications in pollution control ${ }^{13}$.

In the present study it was proposed to evaluate the capacity of cocoa shell, an agricultural waste as a precursor for the preparation of activated carbon material. This adsorbent was successfully used to remove malachite green (MG) dye from aqueous solution. Batch studies were carried out involving processes such as initial dye concentration, contact time, $\mathrm{pH}$ and adsorbent dosage. Equilibrium and kinetic data analysis were conducted to understand sorption process and optimization of various parameters in dye recovery was investigated.

\section{Experimental}

Cocoa shell collected from local agricultural field was air -dried and carbonized with concentrated sulphuric acid in the weight ratio of $1: 1(\mathrm{w} / \mathrm{v})$. The resulting black product was kept in muffle furnace maintained at $550{ }^{\circ} \mathrm{C}$ for $7 \mathrm{~h}$. The carbon obtained was washed with distilled water until it became free from excess acid and dried at $110^{\circ} \mathrm{C}$ for overnight in a hot air oven. The carbonized material was taken out, grounded to fine powder and sieved to $150 \mu \mathrm{m}$ size and stored in a vacuum dessicator.

\section{Preparation of dye solution}

Stock solution of malachite green (Chemical formula: $\mathrm{C}_{23} \mathrm{H}_{25} \mathrm{~N}_{2} \mathrm{Cl}$, M.W.:364.92, C.I. 42000, CAS no.:569-64-2) was prepared by dissolving $1 \mathrm{~g}$ of dye in $1 \mathrm{~L}$ of distilled water to give concentration of $1000 \mathrm{mg} / \mathrm{L}$. The serial dilutions say $20,40,60$ and $80 \mathrm{mgL}^{-1}$ were made by diluting the dye stock solution in accurate proportions. The $\mathrm{pH}$ of dye solutions were adjusted with $0.1 \mathrm{M} \mathrm{NaOH}$ or $0.1 \mathrm{M} \mathrm{HCl}$ using a $\mathrm{pH}$ meter.

\section{Batch adsorption experiments}

Adsorption experiments were carried out in temperature controlled orbital shaker at a constant speed of $125 \mathrm{rpm}$ at $35{ }^{\circ} \mathrm{C}$ using $250 \mathrm{~mL}$ conical flasks containing $100 \mathrm{mg}$ of CSAC with $50 \mathrm{~mL}$ of dye solutions. All the experiments (except the study of $\mathrm{pH}$ effect) were carried out at $\mathrm{pH}$ of 7.0. After agitating the flasks for predetermined time intervals samples were withdrawn from the flasks. The adsorbents were separated from the solution by centrifugation (REMI make) at $2000 \mathrm{rpm}$ for 10 minutes $^{14}$. The absorbance of the supernatant solution was estimated to determine the residual dye concentration ${ }^{15}$, measured at $\lambda_{\max }=617 \mathrm{~nm}$ spectrophotometrically using Elico make UV-Visible spectrophotometer.

The adsorption isotherms were specified at $\mathrm{pH} 7$ for adsorption of MG onto CSAC at $35{ }^{\circ} \mathrm{C}$. Adsorption data obtained from the effect of initial concentration and contact time were employed in testing the applicability of isotherm and kinetic equations, respectively.

\section{Results and Discussion}

\section{Effect of agitation time and initial concentration}

To study the effect of dyes initial concentration and contact time on adsorption uptake, MG solution with initial concentrations $20-80 \mathrm{mgL}^{-1}$ were agitated with $100 \mathrm{mg}$ of CSAC. Theexperimental results of sorption of MG on to CSAC at various initial concentrations are 
shown in Figure 1. The adsorption at different dye concentrations was rapid at the initial stages and then gradually decreases with the progress of adsorption until the equilibrium was reached. The rapid adsorption at the initial contact time can be attributed to the availability of the positively charged surface of activated carbon. As shown in Figure 1, the contact time needed for MG solution to reach equilibrium was $120 \mathrm{~min}$. The results indicated that there was no change in the sorption capacity after $120 \mathrm{~min}$, therefore $180 \mathrm{~min}$ was fixed as the agitation time for isotherm studies. The adsorption capacity at equilibrium $\left(\mathrm{q}_{\mathrm{e}}\right)$ increased from 9.09 to $50.00 \mathrm{mgg}^{-1}$ with an increase in the initial concentrations from $20-80 \mathrm{mgL}^{-1}$.

\section{Effect of adsorbent dosage}

In order to investigate the effect of adsorbent mass on the adsorption, a series of adsorption experiments was carried out with different adsorbent dosages at initial concentration of $40 \mathrm{mg} / \mathrm{L}$ without changing the volume of dye solution $(50 \mathrm{~mL})$ with constant speed of $125 \mathrm{rpm}$ for $3 \mathrm{~h}$ (Figure 2). Similarly the $\mathrm{pH}(7.0)$ and temperature $\left(35^{\circ} \mathrm{C}\right)$ was kept constant. The results follow the expected pattern, in which the percentage sorption increased with increased adsorbent dosage. The increase in carbon dosage is due to adsorbent dosage or due to conglomeration of carbons at higher doses ${ }^{16}$.

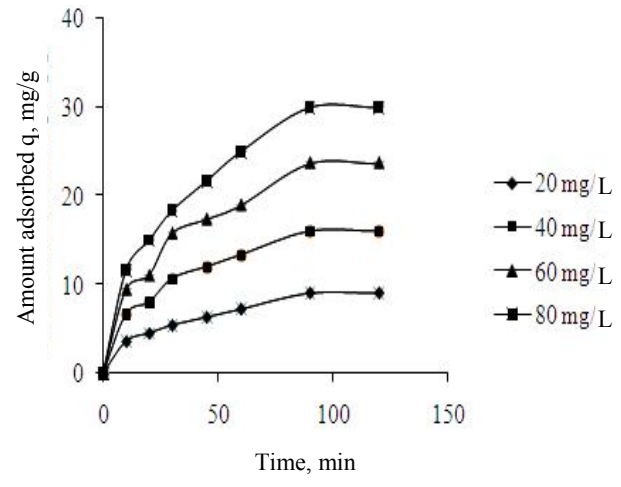

Figure 1. Effect of agitation time on adsorption: Initial concentration variation

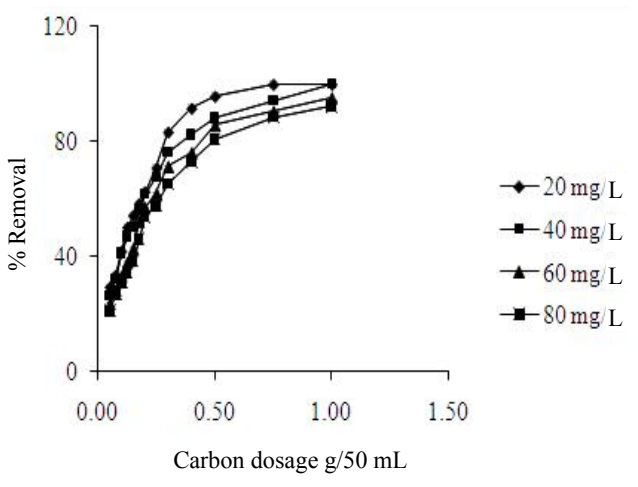

Figure 2. Effect of adsorbent dose on the removal on MG onto CSAC

\section{Effect of $\mathrm{pH}$}

The $\mathrm{pH}$ is one of the most important factor for controlling the adsorption of dye on to the adsorbent. The $\mathrm{pH}$ of the system exerts influence on the adsorptive uptake of adsorbate molecules. The effect of solution $\mathrm{pH}$ was studied between 2 to 10 , initial $\mathrm{pH}$ controlled by the addition of $0.1 \mathrm{M} \mathrm{HCl}$ or $0.1 \mathrm{M} \mathrm{NaOH}$ and agitated with $100 \mathrm{mg}$ of adsorbent for $3 \mathrm{~h}$. The effect of initial $\mathrm{pH}$ of dye solution on the adsorption of MG for initial dye concentration of $40 \mathrm{mg} / \mathrm{L}$ was illustrated in Figure 3. As the $\mathrm{pH}$ increases from 2 to 7, the percent adsorption increases from 33.33 to $86.67 \%$ and from $\mathrm{pH} 7$ to 10 the percent adsorption decreases from 86.67 to $40.00 \%$. The maximum uptake of MG by CSAC was obtained at $\mathrm{pH}$ 7.0. So, $\mathrm{pH} 7.0$ was chosen for the study on adsorption isotherm.

\section{Adsorption isotherms}

The five most common adsorption isotherm models were used to fit the equilibrium adsorption data. These are Langmuir, Freundlich, Temkin, Dubinin-Radushkevich and Flory-Huggins model. 


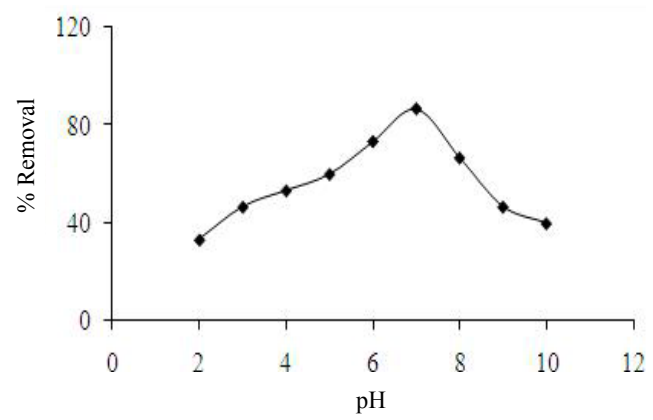

Figure 3. Effect of $\mathrm{pH}$ on the removal of $\mathrm{MG}$ by CSAC

\section{Langmuir isotherm}

Langmuir adsorption isotherm model was usually adopted for homogenous adsorption and it is used successfully in monomolecular adsorption processes ${ }^{17}$. Linear form of Langmuir model was expressed by

$$
\frac{C_{e}}{q_{e}}=\frac{1}{b} Q_{0}+\frac{C_{e}}{Q_{o}}
$$

Where, $\mathrm{C}_{\mathrm{e}}$ is equilibrium constant of dye $(\mathrm{mg} / \mathrm{L}), \mathrm{q}_{\mathrm{e}}$ is amount of dye adsorbed at equilibrium $(\mathrm{mg} / \mathrm{g}), \mathrm{Q}_{0}$ is Langmuir constant related to adsorption capacity $(\mathrm{mg} / \mathrm{g}), \mathrm{b}$ is Langmuir constant related to energy of adsorption capacity $(\mathrm{L} / \mathrm{mg})$. The linear plot of $\mathrm{C}_{\mathrm{e}} / \mathrm{q}_{\mathrm{e}}$ versus $\mathrm{C}_{\mathrm{e}}$ is shown in Figure 4(a). The constants $\mathrm{Q}_{0}$ and $\mathrm{b}$ can be calculated from slope and intercept of the plot and the values are tabulated in Table 1 . The shape of the Langmuir isotherm was investigated by the dimensionless constant separation term $\left(\mathrm{R}_{\mathrm{L}}\right)$ to determine high affinity adsorption. $\mathrm{R}_{\mathrm{L}}$ is calculated as follows:

$$
R_{L}=\frac{1}{1+b C_{0}}
$$

Where, $C_{o}$ is the initial dye concentration $(\mathrm{mg} / \mathrm{L})$. $\mathrm{R}_{\mathrm{L}}$ indicates the type of isotherm to be irreversible $\left(\mathrm{R}_{\mathrm{L}}=0\right)$, favorable $\left(0<\mathrm{R}_{\mathrm{L}}<1\right)$, linear $\left(\mathrm{R}_{\mathrm{L}}=1\right)$ (or) unfavorable $\left(\mathrm{R}_{\mathrm{L}}>1\right)^{18}$. In the present investigation, the $R_{L}$ values were less than one which shows the adsorption process was favorable.

\section{Freundlich isotherm}

The Freundlich isotherm model was chosen to estimate the adsorption intensity of the adsorbate on the adsorbent surface ${ }^{19}$. Linear form of Freundlich model is expressed by

$$
\log C_{e}=\log k_{f}+\frac{1}{n} \log C_{e}
$$

Where, $\mathrm{q}_{\mathrm{e}}$ is dye concentration in solid at equilibrium $(\mathrm{mg} / \mathrm{g}), \mathrm{C}_{\mathrm{e}}$ is dye concentration in solution at equilibrium $(\mathrm{mg} / \mathrm{L}), \mathrm{K}_{\mathrm{f}}(\mathrm{L} / \mathrm{mg})$ and $1 / \mathrm{n}$ are adsorption capacity at unit concentration and adsorption intensity, respectively. $1 / \mathrm{n}$ values indicate the type of isotherm to be irreversible $(1 / \mathrm{n}=0)$, favorable $(0<1 / \mathrm{n}<1)$, unfavorable $(1 / \mathrm{n}>1)$. The linear plot of $\log \mathrm{q}_{\mathrm{e}}$ versus $\log \mathrm{C}_{\mathrm{e}}$ is shown in Figure $4(\mathrm{~b})$. The values of $1 / \mathrm{n}$ and $\mathrm{k}_{\mathrm{f}}$ can be calculated from the slope and intercept respectively and the results are given in Table 1 . The value of $1 / \mathrm{n}$ was less than one indicating the favorable adsorption ${ }^{20}$. 


\section{Dubinin-raduskevich ( $D-R)$ isotherm}

The D-R isotherm was used to determine the characteristic porosity and the apparent free energy of adsorption ${ }^{21}$. The linear form can be represented as

$$
\ln q_{e}=\ln q_{m}-K_{D R} \varepsilon^{2}
$$

Where, $K_{D R}$ is a constant related to the mean free energy of adsorption $\left(\mathrm{mol}^{2} \mathrm{~J}^{-2}\right), \mathrm{q}_{\mathrm{m}}$ is the theoretical saturation capacity $\left(\mathrm{mol} \mathrm{g}^{-1}\right), \varepsilon$ is the polyani potential $\left(\mathrm{J} \mathrm{mol}^{-1}\right)$, which is related to the equilibrium concentration $\left(\mathrm{C}_{\mathrm{e}}, \mathrm{gL}^{-1}\right)$ as follows

$$
\varepsilon=R T \ln \left(1+\frac{1}{C_{e}}\right)
$$

The slope of the plot of $\operatorname{lnq}_{\mathrm{e}}$ versus $\varepsilon^{2}$ gives $\mathrm{K}\left(\mathrm{mol}^{2} \mathrm{~J}^{-2}\right)$ and the intercept yields the adsorption capacity, $\mathrm{q}_{\mathrm{m}}\left(\mathrm{mg} \mathrm{g}^{-1}\right)$. Figure $4(\mathrm{c})$ shows $\mathrm{D}-\mathrm{R}$ plot and the results are given in Table 1. The mean free energy of adsorption $(\mathrm{E})\left(\mathrm{kJmol}^{-1}\right)$ is calculated from the equation ${ }^{22}$.

$$
E=\frac{1}{\sqrt{2 K_{D R}}}
$$

\begin{tabular}{|c|c|c|c|c|}
\hline Models & \multicolumn{4}{|c|}{ Isotherm constants } \\
\hline \multirow{2}{*}{ Langmuir } & $\mathrm{Q}_{\mathrm{m}}, \mathrm{mg} / \mathrm{g}$ & \multicolumn{2}{|c|}{$\mathrm{b} \times 10^{-3}, \mathrm{~L} \mathrm{mg}^{-1}$} & $\mathrm{R}^{2}$ \\
\hline & 37.03 & \multicolumn{2}{|c|}{12.4} & 0.989 \\
\hline \multirow{2}{*}{ Freundlich } & $\mathrm{k}_{\mathrm{f}}, \mathrm{mgg}^{-1}$ & \multicolumn{2}{|c|}{$1 / \mathrm{n}$} & $\mathrm{R}^{2}$ \\
\hline & 1.9817 & \multicolumn{2}{|c|}{0.504} & 0.982 \\
\hline \multirow{2}{*}{ Tempkin } & $\alpha, \mathrm{L} \mathrm{mol}^{-1}$ & $\beta$ & $\mathrm{b}$ & $\mathrm{R}^{2}$ \\
\hline & 0.36 & 20.87 & 122.7 & 0.988 \\
\hline \multirow{2}{*}{$\begin{array}{c}\text { Dubinin- } \\
\text { Radushkevich }\end{array}$} & $\frac{\mathrm{q}_{\mathrm{m}}}{\mathrm{mgg}^{-1}}$ & $\begin{array}{c}\mathrm{K}_{\mathrm{DR}}, \\
10^{-7} \mathrm{~mol}^{2} \mathrm{~J}^{-2}\end{array}$ & $\begin{array}{c}\mathrm{E}, \\
\mathrm{kJmol}^{-1}\end{array}$ & $\mathrm{R}^{2}$ \\
\hline & 1 & 3.161 & 0.4 & 0.947 \\
\hline \multirow[t]{2}{*}{ Flory-Huggins } & $\begin{array}{c}\mathrm{K}_{\mathrm{FH}} \\
10^{3} \mathrm{~L} \mathrm{~g}^{-1}\end{array}$ & $\mathrm{n}$ & $\begin{array}{c}\Delta \mathrm{G}^{\circ} \\
\mathrm{kJmol}^{-1}\end{array}$ & $\mathrm{R}^{2}$ \\
\hline & 40.95 & 11.35 & -10.5 & 0.953 \\
\hline
\end{tabular}

Table 1. Results of various isotherm plots for the adsorption of MG onto CSAC

\section{Tempkin isotherm}

The Tempkin isotherm model predicts a uniform distribution of binding energies over the population of surface binding adsorption ${ }^{23}$. The model was chosen to determine the adsorption potentials of the adsorbent for adsorbates. The Tempkin isotherm is applied in the following form

$$
q e=\frac{R T}{b} \ln A C_{e}
$$

The linear form of Tempkin equation is

$$
q_{e}=\beta \ln \alpha+\beta \ln C_{e}
$$

$\mathrm{T}$ is the absolute temperature in Kelvin, $\mathrm{R}$ is the universal gas constant, $8.314 \mathrm{~J}(\mathrm{~mol} \mathrm{~K})^{-1}$, $\mathrm{b}$ is the Tempkin constant related to heat of sorption $(\mathrm{J} / \mathrm{mg})$. The Tempkin constants $\alpha$ and $\mathrm{b}$ are calculated from the slope and intercept of $\mathrm{q}_{\mathrm{e}}$ versus $\ln \mathrm{C}_{\mathrm{e}}$ (Figure $4(\mathrm{~d})$ ) and parameters are given in the Table 1. 

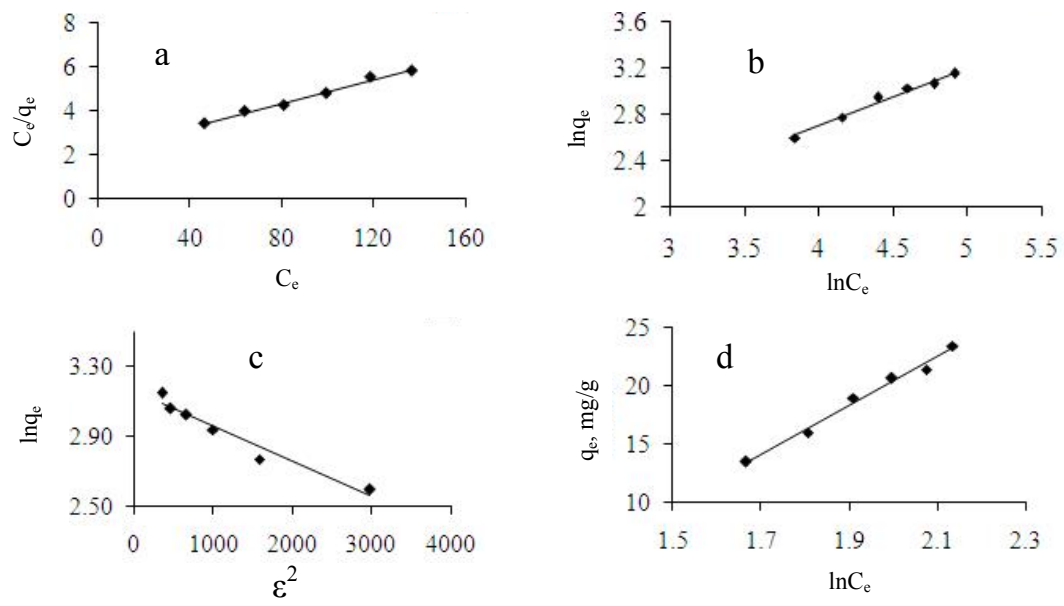

Figure 4. Adsorption isotherm plots for MG onto CSAC, (a) Langmuir plot, (b) Freundlich plot, (c) Dubinin-Raduskevich (D-R) plot, (d) Tempkin plot

where,

\section{Flory-Huggins model}

$$
\beta=\frac{R T}{b},
$$

The Flory-Huggins model was used to determine for the degree of surface coverage characteristics of the adsorbate on the adsorbent ${ }^{24}$. The linear form of the Flory-Huggins equation is expressed as

$$
\ln \left(\frac{\theta}{C_{0}}\right)=\ln K_{F H}+n \ln (1-\theta)
$$

Where, $\theta=\left(1-\mathrm{C}_{\mathrm{e}} / \mathrm{C}_{\mathrm{o}}\right)$ is the degree of surface coverage, $\mathrm{n}$ is the number of dye occupying adsorption sites, $\mathrm{K}_{\mathrm{FH}}$ is the equilibrium constant $\left(\mathrm{L} \mathrm{mol}^{-1}\right) . \mathrm{K}_{\mathrm{FH}}$ and $\mathrm{n}$ can be determined by plotting $\ln \left(\theta / \mathrm{C}_{\mathrm{o}}\right)$ versus $\ln (1-\theta)$ (figure not shown) and the parameters are given in Table1. $\mathrm{K}_{\mathrm{FH}}$ and $\Delta \mathrm{G}^{0}$ are related as follows

$$
K_{F H}=\exp \left(\frac{-\Delta G_{0}}{R T}\right)
$$

Where, $\Delta G^{0}$ is the standard free energy change, $R$ is the universal gas constant and equal to $8.314 \mathrm{~J} \mathrm{~mol}^{-1} \mathrm{~K}^{-1}$ and $\mathrm{T}$ is the absolute temperature. The values of $\Delta \mathrm{G}^{0}$ calculated was negative which shows that the adsorption process is spontaneous in nature and supports an exothermic nature.

\section{Adsorption kinetics}

Kinetic studies are necessary to optimize different operation condition for the sorption of dyes. The kinetics of MG onto CSAC was analyzed using pseudo- first order and pseudosecond order kinetic models.

\section{Pseudo - first order kinetic model}

It is based on the fact that the change in dye concentration with respect to time is proportional to the power one $\mathrm{e}^{25}$. The differential equation is described as follows: 


$$
\frac{d q_{t}}{d t}=k_{1}\left(q_{e}-q_{t}\right)
$$

Where, $\mathrm{q}_{\mathrm{e}}$ and $\mathrm{q}_{\mathrm{t}}$ are the adsorption capacity $(\mathrm{mg} / \mathrm{g})$ at equilibrium and time $\mathrm{t}$, respectively and $\mathrm{k}_{1}$ is the rate constant $\left(\mathrm{min}^{-1}\right)$ of pseudo first order kinetic model. The integrated linear form of the model is as follows:

$$
\log \left(q_{e}-q_{t}\right)=\log q_{t}-\frac{k_{1}}{2.303}
$$

A plot of $\log \left(\mathrm{q}_{\mathrm{e}}-\mathrm{q}_{\mathrm{t}}\right)$ versus $\mathrm{t}$ gives a linear line (Figure 5(a)) from which the values of $\mathrm{k}_{1}$ and $\mathrm{q}_{\mathrm{e}}$ can be determined from the slope and intercept respectively and presented in Table 2 . This value showed that the $\mathrm{q}_{\mathrm{e}}$ calculated was not equal to $\mathrm{q}_{\mathrm{e}}$ experimental, although the values of $\mathrm{R}^{2}$ are satisfactory. This shows that the kinetics for the entire process did not follow the pseudo-first order model.

\section{Pseudo - second order kinetic model}

The adsorption mechanism over a complete range of the contact time is explained by the pseudo - second order kinetic model ${ }^{26}$. The differential equation is described as follows:

$$
d q_{t}=k_{2}\left(q_{e}-q_{t}\right)^{2}
$$

Where, $\mathrm{q}_{\mathrm{e}}$ and $\mathrm{q}_{\mathrm{t}}$ are the adsorption capacity $(\mathrm{mg} / \mathrm{g})$ at equilibrium and time $\mathrm{t}$, respectively and $k_{2}$ is the rate constant of pseudo second order adsorption ( $\mathrm{g} / \mathrm{mg} \mathrm{min}$ ).

Table 2. Calculated kinetic parameters for the adsorption of MG onto CSAC

\begin{tabular}{ccccc}
\hline Concentration, mg/L & 20 & 40 & 60 & 80 \\
\hline Pseudo-first order kinetics & & & & \\
$\mathrm{k}_{1} \times 10^{-2}, \mathrm{~min}^{-1}$ & 2.07 & 2.53 & 2.07 & 2.53 \\
$\mathrm{q}_{\mathrm{e}(\mathrm{cal})}, \mathrm{mg} / \mathrm{g}$ & 6.95 & 12.33 & 17.86 & 24.71 \\
$\mathrm{q}_{\mathrm{e}(\mathrm{exp})}, \mathrm{mg} / \mathrm{g}$ & 9.09 & 16.00 & 23.68 & 30.00 \\
$\mathrm{R}^{2}$ & 0.994 & 0.988 & 0.963 & 0.990 \\
Pseudo-second order kinetics & & & & \\
$\mathrm{k}_{2} \times 10^{-3}, \mathrm{~g} / \mathrm{mg}$ min & 2.5 & 1.8 & 1.73 & 1.03 \\
$\mathrm{q}_{\mathrm{e}(\mathrm{cal})}, \mathrm{mg} / \mathrm{g}$ & 11.62 & 20.00 & 25.00 & 35.7 \\
$\mathrm{~h}$ & 0.34 & 0.7 & 1.08 & 1.3 \\
$\mathrm{R}^{2}$ & 0.996 & 0.998 & 0.999 & 0.999 \\
\hline
\end{tabular}

The linearised form of the above model is

$$
\frac{t}{q_{t}}=\frac{1}{k_{2} q_{e}^{2}}+\frac{t}{q_{e}}
$$

The initial adsorption rate, $\mathrm{h}(\mathrm{mg} / \mathrm{g} \min )$, as $\mathrm{t} \rightarrow 0$ can be defined as

$$
h=k_{2} q_{e}^{2}
$$

A plot of $t / q_{t}$ versus $t$ gives a linear relationship (Figure 5(b)), from which $\mathrm{q}_{\mathrm{e}}$ and $\mathrm{k}_{2}$ can be determined from the slope and intercept of the plot respectively and presented in Table 2 . The values of $\mathrm{q}_{\mathrm{e}}$ calculated show good agreement with experimental data. The correlation coefficient $\mathrm{R}^{2}$ was close to unity. Thus the sorption of MG by CSAC could be approximated more appropriately by the pseudo-second order model $^{27}$, supporting the assumption of chemisorptions as the rate-limiting mechanism through sharing or exchange of electrons between sorbent and sorbate ${ }^{28}$. 

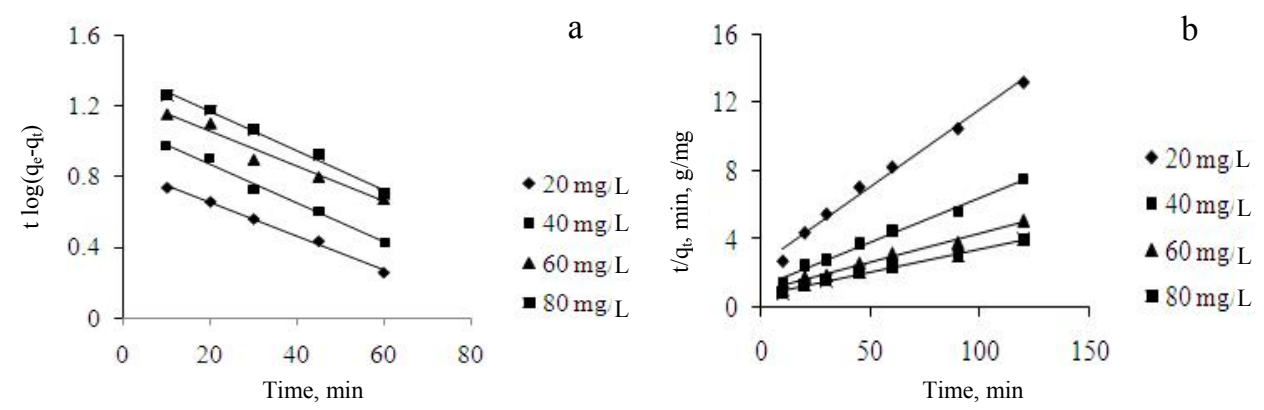

Figure 5. Kinetic plots for the adsorption of MG onto CSAC, (a) Pseudo- first order plot, (b) Pseudo- second order plot

\section{Conclusion}

The present study shows that the agricultural waste material, cocoa shell, can be effectively used as an adsorbent for the removable of malachite green from aqueous solution. The adsorption characteristics have been examined by initial $\mathrm{pH}$, contact time, initial concentration and adsorbent dose. The equilibrium data were evaluated by Langmuir, Freundlich, Tempkin, Dubinin-Radushkevich and Flory-Huggins isotherms. Kinetic studies showed that the adsorption process followed the pseudo-second order model and pseudosecond order rate constant, $\mathrm{k}_{2}$, decreases form $2.5 \times 10^{-3}$ to $1.03 \times 10^{-3} \mathrm{~g} / \mathrm{mg}$ min with increase in initial dye concentration for CSAC. Based on the data of present study, it could be employed that CSAC is an effective adsorbent for the removal of $\mathrm{MG}$ from aqueous solution.

\section{References}

1. Jalajaa D, Manjuladevi M and Saravanan S V, Poll Res., 2009, 28(2), 287-290.

2. Allen S J and Koumanova B, J Univ Chem Tech Metallurgy, 2005, 40(3), 175-192.

3. Muthukumar M and Selvakumar N, Dyes Pigments, 2004, 62(3), 221-228.

4. Shi B, Li G, Wang C, Feng C and Tang H, J Hazard Mater., 2007, 143, 567-74.

5. Majewska-Nowak K, Winnicki T and Wisniewski J, Desalination, 1989, 71, 127-132.

6. Kim T H, Park C, Yang J and Kim S, J Hazard Mater., 2004, 112(1-2), 95-103.

7. Dong Y, Han Z, Liu C and Du F, Sci Total Environ., 2010, 40, 2245-2253.

8. $\quad$ Suna D, Zhang, Wu y and Liu X, J Hazard Mater., 2010, 181, 335-342.

9. Amin N K, J Hazard Mater., 2009, 165(1-3), 52-62.

10. Ho Y S and McKay G, Resource Conservation Recycling, 1999, 25(3), 171-193.

11. Ahmad bin Juosh, Cheng W H, Lo W M, Ali Nora'aini and Megat Mohd. Noor M J, Desalination, 2005, 182, 347-353.

12. Amit Bhatnagar and Minocha A K, Ind J Chem Tech., 2006, 13, 203-217.

13. Choy K K H, McKay G and Porter J F, Resource Conservation Recycling, 1999, 27(1-2), 57-71.

14. Bhatti H N, Nasir A W and Hanif M A, Desalination, 2010, 253, 78-87.

15. Vogel A I, A Textbook of Quantitative Inorganic Analysis $\left(3^{\text {rd }} \mathrm{Ed}\right)$., ELBS Longmans Limited, London, 1969.

16. Kannan N and Srinivasan T, Indian J Environ Protect., 1998, 18(3), 194.

17. Langmuir I, J Am Chem Soc., 1918, 40, 1361-1403. 
18. Sathish Manocha, Vanraj B.Chauhan and Manocha LM, Carbon Sci., 2002, 3(3), 133-141.

19. Freundlich H M F, Z Phys Chem., 1906, 57, 385-471.

20. Trey Bell R K, Mass Transfer Operations (10 $0^{\text {th }}$ Ed.), McGraw Hill, New York, 1998.

21. Ahmed El Nemr, Ola Abdelwahab, Amany El-Sikaily and Azza Khaled, J Hazard Mater., 2009 161, 102-110.

22. Kundu S and Gupta A K, Colloid Surfaces A: Physiochem Engg Aspects, 2006, 273, 121-128.

23. Abdelwahab O, Desalination, 2008, 222, 357-367.

24. Aysun Ergene, Kezban Ada, Sema Tan and Hikmet Katircioglu, Desalination, 2009, 249, 1308-1314.

25. Lagergren S, Kung Sven Veten Hand., 1898, 24, 1-39.

26. Ho Y S and Mc Kay G, Process Biochem., 1999, 34, 450-465.

27. Li Wang, Jian Zhang, Ran Zhao, Cong Li, Ye Li and Chenglu Zhang, Desalination, 2010, 254, 68-74.

28 Zohra Belala, Mejdi Jeguirim, Meriem Belhachemi, Fatima Addoun and Gwenelle Trouve, Desalination, 2011, 271, 80-87. 


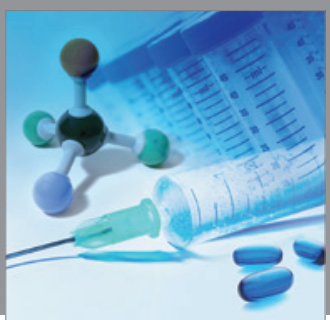

International Journal of

Medicinal Chemistry

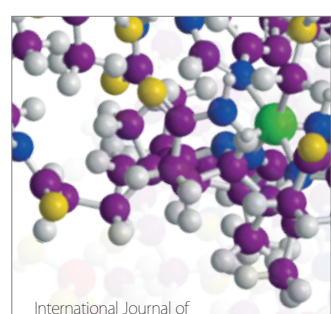

Carbohydrate Chemistry

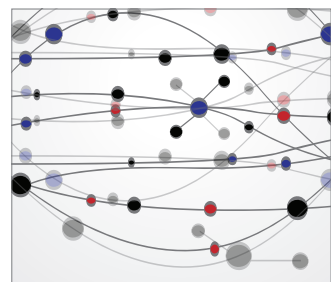

The Scientific World Journal
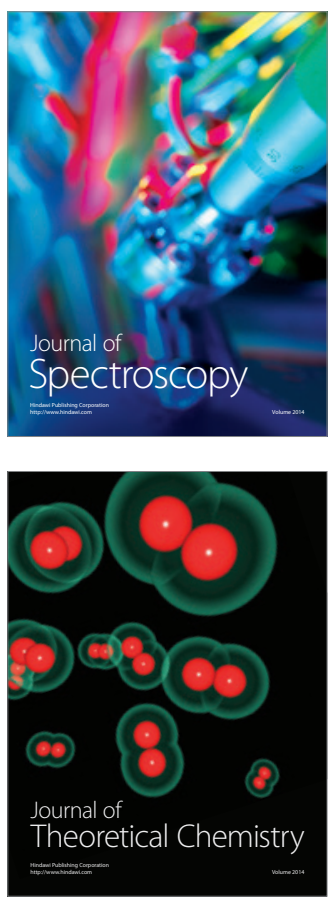
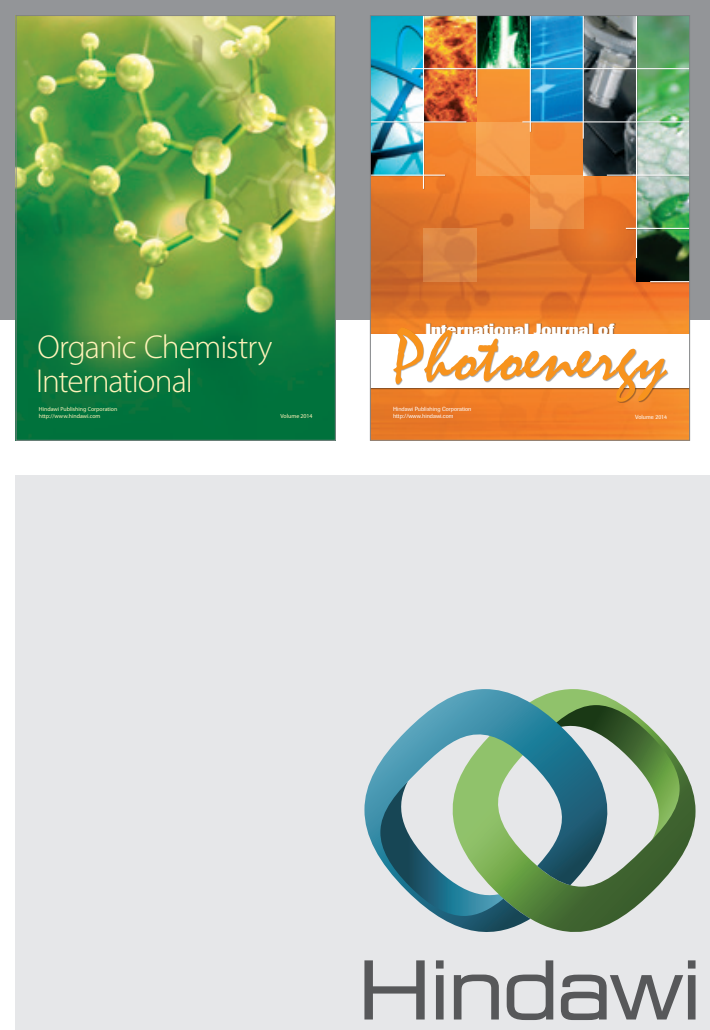

Submit your manuscripts at

http://www.hindawi.com
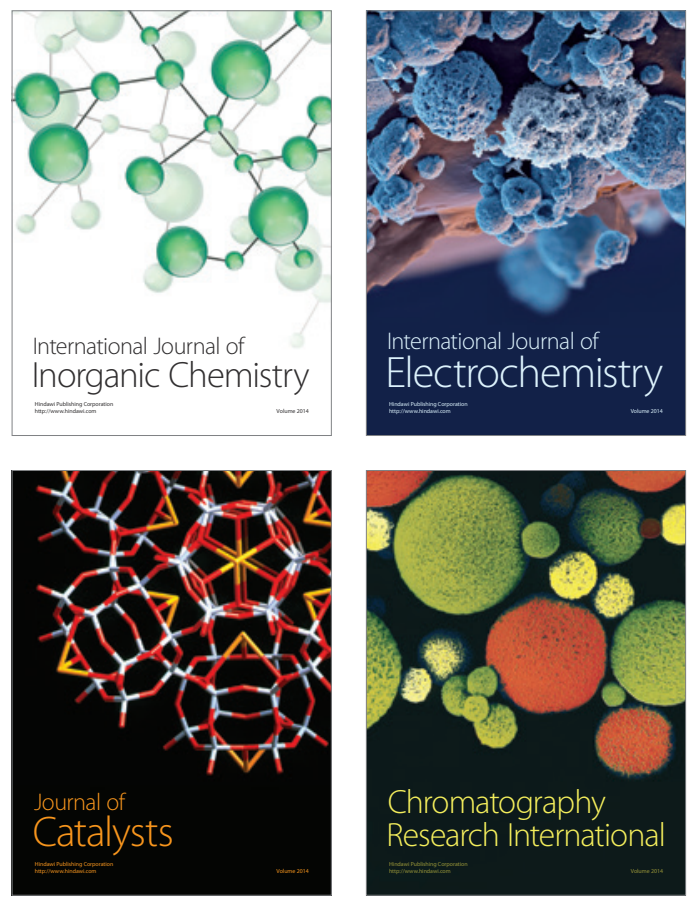
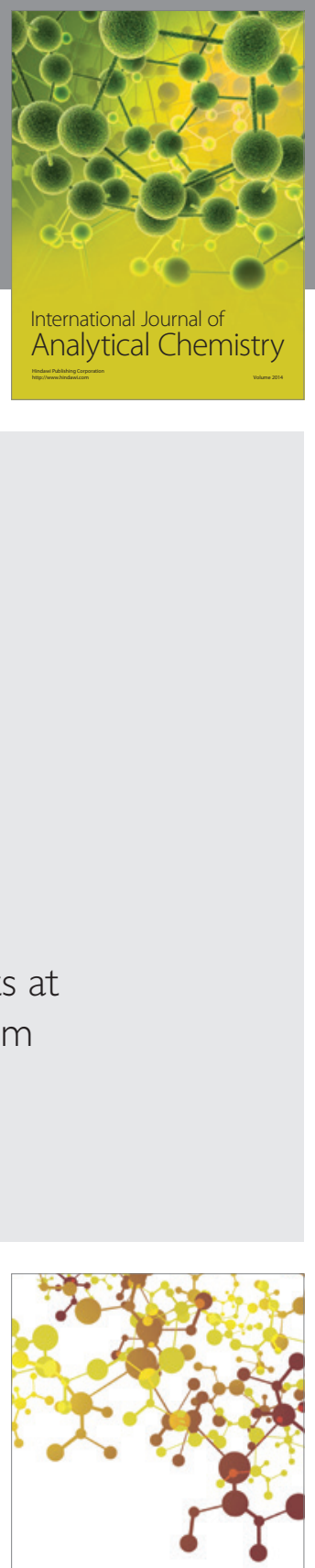

Journal of

Applied Chemistry
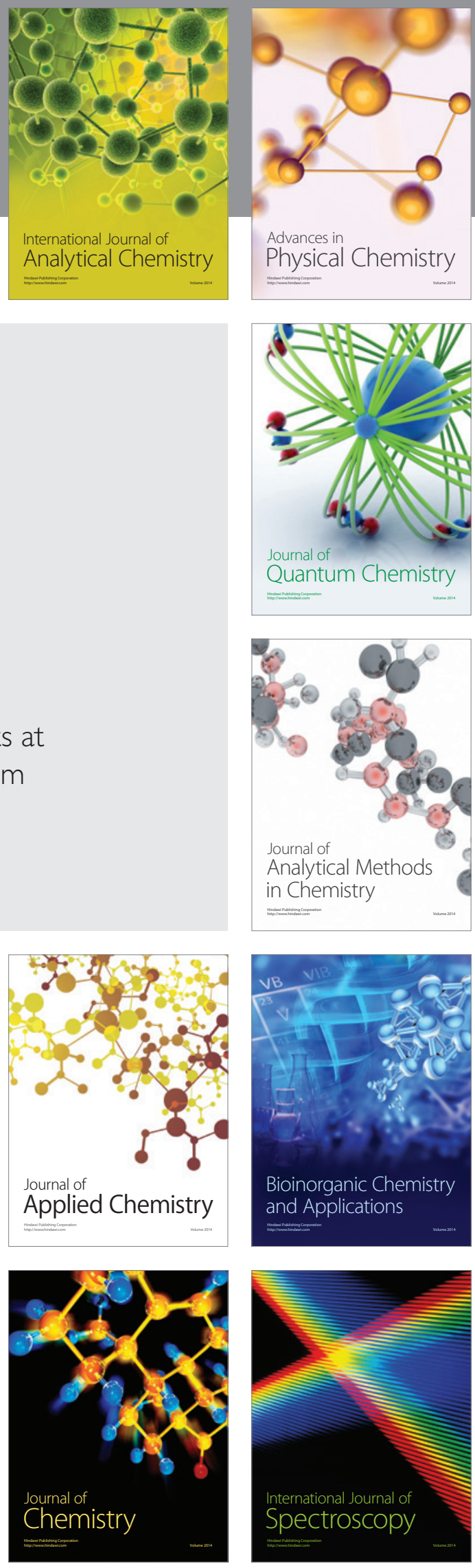